American Journal of Animal and Veterinary Sciences 7 (2): 48-54, 2012

ISSN 1557-4555

(C) 2012 Science Publications

\title{
Space Requirements to Optimize Welfare and Performance in Group Housed Pigs-A Review
}

\author{
Alexandra L. Whittaker, \\ William H. Van Wettere and Paul E. Hughes \\ School of Animal and Veterinary Sciences, \\ University of Adelaide, Roseworthy, SA 5371, Australia
}

\begin{abstract}
Problem statement: In most countries of the world where there are legislation or guidelines pertaining to the commercial farming of domestic swine, figures are quoted for minimum space allocation for various ages and life stages of the animals. These figures are generally based on professional judgment and are in common usage, but there is a growing trend and an expectation that regulatory decision making should be informed by evidence based studies. Approach: A literature review was conducted on experiments involving manipulation of space inputs in pigs. Studies were chosen that focussed on the effect of space on standard production parameters and well established welfare measures. Results: Agonistic behavior and its resultant effects on welfare in group housed systems is a key industry focus, yet, a failure to quantify the effects of space allocation per se is a confounding variable in many studies looking into this important aspect of husbandry. Conclusion/Recommendations: Whilst it seems that some general conclusions can be made, ascertaining figures for space allocation (especially in sows) remains problematic. This would appear to be an area worthy of further research using well-controlled studies, taking into consideration the increased size of the modern pig.
\end{abstract}

Key words: Remains problematic, group housed systems, commercial farming, minimum space allocation, confounding variable, resulting injury

\section{INTRODUCTION}

Intensive housing of pigs developed to make efficient use of available space without compromising productivity parameters (Bogner, 1982) and this space might be seen as one of the limiting factors in further growth in breeding productivity. In relation to animal welfare, regard for the animal as a sentient being, as well as the public's increasing interest in farming industries, provides further reasons for concern in this area. Space provided to animals is one easily recognizable aspect of husbandry systems that is perceived by the public to imply that welfare is poor.

In the pig industry, this might include space provided in singly housed animals and whether it allows performance of normal behaviors, or that provided in group housed systems where agonistic interactions and the resulting injury and psychological distress are more likely to be a welfare concern. In relation to group housed animals and minimization of aggression there are also likely to be complex interactions between space provided, group size, mixing strategies, resource availability and social structure of the individuals within the group.

Corresponding Author: Alexandra L. Whittaker, School of Animal and Veterinary Sciences, The University of Adelaide, Roseworthy, SA 5371, Australia, Tel: 00-61-08 83037868

Recommendations (legislated or advisory in Codes) for space requirements in adult pigs are few, probably based on current practice and no doubt reflect the lack of scientific literature in this area. Within Australia recommendations range from $1.4-1.8 \mathrm{~m}^{2}$ per pig (Cale, 1979). In the EU directive the floor area available for group-housed gilts and sows must be at least $1.64 \mathrm{~m}^{2}$ and $2.25 \mathrm{~m}^{2}$ respectively, with an increase of $10 \%$ of space allowance being necessary for groups of animals of less than six and a similar reduction of $10 \%$ when groups of 40 or more animals are housed Council Directive 2001/88/EC, 2001.

Given the general trend towards group housing of sows in most jurisdictions Council Directive 2001/88/EC, 2001; Model Code of Practice for the Welfare of Animals: Pigs, 1998, brought about by bans on the use of tethers and reduction in the allowed stall housing duration for pregnant sows questions relating to management of group housed sows to optimize their welfare become all the more important. Therefore and rightly so, this is an important area of current research focus within the pig industry. However, in order to answer fully, complex questions relating to such issues 
as aggression management, enrichment, social structures and pen design, a definitive answer as to whether space allocation does indeed have any effects on animal well-being and a characterization of these effects is needed. Without such an evaluation there is a risk that space allocation per se may confound studies into these other important areas. In addition, it is generally acknowledged that the domestic swine have become larger over the last few decades as a result of improved genetics and this may well have effects on the space allowance that the individual animal requires. Whilst regulatory stipulations on space allowance have gradually increased with further iterations of these documents, it is often unclear as to the welfare science base for these recommendations. As there becomes increased media and public interest in many animal based industries, accompanied by this is a growing expectation by the public and legislators alike, that regulation of animal use is based on sound animal welfare science. Given this backdrop, a review of the literature around space allocation studies in pigs was conducted to ascertain current knowledge and, where necessary to provide a rationale for further studies. This review specifically examines the literature on space allocation (defined as the surface area available for each individual) per se, in group housed pigs, with respect to its effect on animal welfare and productivity. Whilst a primary focus of attention in the industry is on group housing of sows, in order to establish potential adverse effects of changing space allocations, the body of literature on grower- finisher pigs were considered as well as that related to the female pig.

It has been suggested that there are qualitative and quantitative space requirements. Qualitative space is the space required for performance of normal activities such as feeding, exploring, carrying out social behavior or for animals to remove themselves from visual contact with others. This implies a need for each animal to have an area of empty space around it to avoid continuous physical contact with others and to be able to defend this territory against invasion from conspecifics (ECVSC, 1997). The concept of "crowding" has been introduced to describe movement or activity restriction caused by the physical presence of others (Fraser and Broom, 1990). The variables involved in this concept are number of animals, stocking density, social space (determined by reactions between animals) and the space itself (Myers cited in ECVSC, 1997). A large number of studies on the consequences of crowding have been performed in laboratory rodents. Noted adverse effects include: decreased gonadal activity in males and a decline in reproductive parameters in general, increased infant mortality, an increase in aggressiveness, disruption of normal social behavior and an increase in adrenal activity (Bronson and Eleftheriou, 1963; Christian, 1955). This study also showed that some animals withdrew from social interaction and only the strongest animals were able to reproduce (Myers cited in ECVSC, 1997). Aggression is likely to be the key causative factor for the severe consequences of crowding on the above parameters (ECVSC, 1997).

\section{Production effects:}

Grower/Finisher pigs: A large number of studies have been conducted in growing pigs to look at the effect of space on production parameters, such as average daily gain and daily food intake (Table 1 summarizes a number of these).

Many of these studies have varied group size to change the space allocation per pig but nevertheless they give a good indication of effects that may be seen due to "crowding". A reduction in piglet performance has been shown in larger groups with reduced floor space (Hyun et al., 1998; Wolter et al., 2000). In a well controlled study in young grower finisher pigs reported by Gonyou and Stricklin (1998), crowding was demonstrated to decrease daily gains and food intake (though had no resultant effect on efficiency. Arranging pigs in groups of 8,12 or 16 at a constant space allocation of $0.36 \mathrm{~m}^{2 /}$ pig resulted in slower weight gain than among groups with double space allocation and the group size reduced to one-half (Gehlbach et al., 1966; Jensen and Curtis, 1976; Moser et al., 1985; Pickett et al., 1969). Similarly in grower finisher pigs decreasing space allowance was shown to negatively affect weight gain (Street and Gonyou, 2008) and food conversion (Moser et al., 1985).

Jensen (1971) did not find any improvement in performance by increasing the available space for starter pigs since $0.28-0.35 \mathrm{~m}^{2}$ (Jensen et al., 1966) whilst, in another study a better growth rate was shown by increasing space allowance per pig (Randolph et al., 1981). Brumm (1996) noted a similar response on increasing space allowance from 0.56-0.78 $\mathrm{m}^{2} / \mathrm{pig}$ (however this change was brought about by varying group size) (Brumm and Miller, 1996). In another study separating out the density and group size, pigs were shown to have a better food intake, weight gain and feed conversion efficiency when housed at the lowest density and in the smallest group size (Heitman et al., 1961). Similar results were obtained by (Brumm, 1996) and by (Spicer and Aherne, 1987) who noted that weaned pigs had better growth and spent more time feeding when penned in groups of two rather than in groups of four. 
American J. Animal \& Vet. Sci., 7 (2): 48-54, 2012

Table 1: Summary table of a number of studies comparing the effects of space allocation on productivity parameters

\begin{tabular}{|c|c|c|c|c|c|}
\hline Reference & $\begin{array}{l}\text { Age } \\
\text { of pig }\end{array}$ & $\begin{array}{l}\text { Space allocation } \\
\text { per pig }\left(\mathrm{m}^{2}\right)\end{array}$ & $\begin{array}{l}\text { Pigs/ } \\
\text { pen }\end{array}$ & Endpoints & $\begin{array}{l}\text { Result with less } \\
\text { floor space }\end{array}$ \\
\hline \multirow[t]{4}{*}{ Randolph et al (1981) } & Grower-Finishers & $0.33,0.66$ & 5,10 (factorial design) & Weight Gain & $\begin{array}{l}\text { Decreased } \\
\text { (Group size no effect) }\end{array}$ \\
\hline & & & & Food Intake & $\begin{array}{l}\text { Decreased -not } \\
\text { statistically significant) } \\
\text { (Group size no effect) }\end{array}$ \\
\hline & & & & Aggression & Increased \\
\hline & & & & Activity & No Effect \\
\hline \multirow[t]{3}{*}{ Heitman et al. (1961) } & Grower-Finishers & $0.45,0.9,1.8$ & $\begin{array}{l}3,6,12 \\
\text { (Factorial design) }\end{array}$ & Weight Gain & $\begin{array}{l}\text { Decreased } \\
\text { (Group size no effect) }\end{array}$ \\
\hline & & & & Food Intake & $\begin{array}{l}\text { No Effect } \\
\text { (Increased } \\
\text { group size decreases) }\end{array}$ \\
\hline & & & & Food Conversion Efficiency & $\begin{array}{l}\text { Increased } \\
\text { (Increased } \\
\text { group size decreases) }\end{array}$ \\
\hline \multirow[t]{2}{*}{ Brumm (1996) } & Barrows & $0.65,0.84,1.02$ & 12 & Weight Gain & Increased \\
\hline & & & & Food intake & No Effect \\
\hline \multirow[t]{4}{*}{ Beattie et al. (1996) } & Grower-Finisher & $0.5,1.1,1.7,2.3$ & 6 & Exploratory behavior & Decreased \\
\hline & & & & Locomotor Activity & Decreased \\
\hline & & & & Weight gain & Increased \\
\hline & & & & Food Conversion Efficiency & Increased \\
\hline \multirow[t]{5}{*}{ Young et al. (2008) } & Gilts & $0.77,1.13$ & 22,15 & Growth Rate & No Effect \\
\hline & & & & Back fat & No Effect \\
\hline & & & (used to change the space & Pigs Produced & No Effect \\
\hline & & & allowance per pig) & Removal Rate & No Effect \\
\hline & & & & Age of puberty attainment & $\begin{array}{l}\text { Decreased number attained } \\
\text { Puberty at younger age }\end{array}$ \\
\hline \multirow[t]{3}{*}{ Kuhlers et al. (1985) } & Gilts & $0.63,1.25$ & 16,8 & Pigs per litter & Decreased \\
\hline & & & & Pigs/litter born alive & Decreased \\
\hline & & & $\begin{array}{l}\text { (used to change space } \\
\text { allowance per pig) }\end{array}$ & $\begin{array}{l}\text { Number of Corpora Lutea } \\
\text { at day } 30 \text { gestation }\end{array}$ & No Effect \\
\hline
\end{tabular}

Interestingly, for one experimental location, Brumm (1996) reported a quadratic (rather than linear) response to pig weight, daily gains and food intake with increasing space allocation, with pigs with an intermediate space allocation having the best performance and those with the most space having the poorest performance. The authors suggested that there may be a possible genetic or facility interaction that might explain this. A plateau in increasing performance with increasing space allowance was also shown in another study conducted. Improved weight gains and feed conversion efficiency were shown in the first 3 space allocation pens but not in the fourth pen size, indicating that space allowance beyond $1.7 \mathrm{~m}^{2} / \mathrm{pig}$ is not beneficial (Beattie et al., 1996).

Sows/gilts: From the earlier discussion it can be seen that crowding has been shown to have a number of negative effects on production parameters in growing pigs. In adult females, from an industry point of view, effects on reproduction parameters are of the most importance. This area is less studied in comparison with the grower-finisher groups and determining optimum space requirements for sows in groups remains problematic due to the lack of published evidence.

The effect of space restriction on performance in barrows and gilts and age of puberty attainment in gilts was studied by Ford and Teague (1978). A control space allocation of $0.37 \mathrm{~m}^{2}$ per pigs was used with an additional $0.09 \mathrm{~m}^{2}$ added for each additional $13.6 \mathrm{~kg}$ increase in body weight. Restricted space levels were at 75 and $50 \%$ of these values. This study found no significant differences between average daily gain and feed efficiency at $75 \%$ of the space allowance, although at $50 \%$ there was a decrease in these parameters with no associated change in feed consumption. Average age at oestrus was not affected by crowding.

In a similar long term study looking at the effects of space during rearing of gilts (from $38 \mathrm{~kg}$ body weight) on growth and future reproductive parameters there was found to be no differences between parameters such as growth rate, back fat thickness and loin depth at the two space allocations $\left(1.13 \mathrm{~m}^{2}\right.$ and $0.77 \mathrm{~m}^{2}$ per gilt). It also had no further effect on total pigs produced over 3 parities or on removal rate, although animals reared with the larger space allocation were more likely to attain puberty at a younger age and consequently produced more pigs over the three parities than their counterparts. It should be noted that the space allowance in this study was varied by increasing group number and therefore this adds an additional confounding variable (Young et al. 2008). In contradiction to this, Kuhlers et al. (1985) found that gilts raised in pens with larger space allowance $(1.25$ $\mathrm{m}^{2}$ ) later farrowed more pigs per litter and had more 
pigs per litter born alive than those with half as much space. However, care should be taken in interpretation of these results since space restriction was again achieved by variation in the group size and a relatively small number of animals were used in this study.

In a study by Andersen et al. (2000), insufficient space allowance in group housed systems for sows was shown to lead to exclusions of low ranking individuals and thus cause them to have a greater heat loss. A kennelling system was used in this study and the effects of space per se were not evaluated. Heat loss may have consequent effects on production although this was not reported on in this study (Andersen et al., 2000).

\section{Effects on behavior/welfare:}

Growers: Study by Beattie et al. (1995) showed that enriching the environment, by the addition of straw and peat and providing four times the recommended space allowance (Humik and Lewis, 1991) reduced behaviors such as persistent nosing of penmates and tail-biting in growing pigs. There is also evidence that decreasing space allowance leads to increased agonistic behavior (Ewbank and Bryant, 1972; Meunier-Salaun et al., 1987). It has also been claimed that the incidence of cannibalism and tail biting increases as space allowance decreases (Jensen, 1971; Randolph et al., 1981). A later study teased apart the individual contribution played by space and enrichment in reducing abnormal behaviors (Beattie et al., 1996). The results suggest that increased space per se without enrichment, in comparison with enriched areas, increased harmful social behaviors (even with a maximal space allowance) and caused animals to show less locomotory and exploratory behavior. The authors concluded that enrichment played a greater role in determining behavior than did space allocation.

Several studies show a major decrease in resting time correlated with large group size (Ewbank and Bryant, 1972; Randolph et al., 1981; Ross and Curtis, 1976). In an animal that spends a large amount of time resting (Fraser and Broom, 1990) this may be of concern for well-being. An increased frequency of oesopho-gastric lesions have also been found in growing pigs housed at a lower space allowance $(0.55$ $\mathrm{m}^{2}$ versus $1.1 \mathrm{~m}^{2}$ ). Whilst these lesions are likely to be of multi-factorial origin their presence is likely to induce pain and therefore have consequent negative effects on welfare and thus their exacerbation by crowding is an issue for consideration within the scope of this review (Pickett et al., 1969).

Sows: Efforts to quantify space requirements to maximize performance and some aspects of good welfare have been made in sows. Salak- Johnson looked at different floor space allowances for pregnant sows in pens to determine the impacts of space on sow performance, productivity and body lesions during two consecutive farrowing. Treatment groups of five sows per pen were assigned to $1.4,2.3$, or $3.3 \mathrm{~m}^{2}$ of floor space/sow. A comparison was also made between five sows in individual stalls with $1.34 \mathrm{~m}^{2}$ of space each. Results generally showed that as floor space increased, body weight and back fat increased, but as space decreased, skin lesion scores (indicative of agonistic interactions) increased. Although the effects of gestation system were found and lesion scores were greater as space decreased, differences in productivity traits were unremarkable with respect to sow welfare or performance in comparison with industry norms. Similar to the study in growing pigs, linear and quadratic relationships were found in many of the parameters examined, suggesting a narrow range of space allocations optimize outcomes. There was also an interaction of space treatment and parity for some of the parameters measured (sow mean body weight, d-110 body weight, back fat, litter size and litter and piglet body weight and gain), with most effects in parity 2, 3 and 4 sows. The authors concluded that no optimal space allocation could be identified from the results (Salak-Johnson et al., 2007). In another study where parity effects were considered it was stated that multiparous sows need more space for suitable resting accommodation than primiparous ones ( a minimum of $1.3 \mathrm{~m}^{2} / \mathrm{sow}$ versus $0.95 \mathrm{~m}^{2} / \mathrm{sow}$ ) (Tober 1996 cited in ECVSC, 1997).

Another study looked at established groups of six pregnant, multiparous sows to compare four pen sizes providing 2.0, 2.4, 3.6 or $4.8 \mathrm{~m}^{2}$ per sow. Video recording was made to determine general behavior and social interactions. As space allowance increased, time spent rooting increased whilst time spent sitting and standing inactive were both reduced. Also as space allowance decreased, frequency of social interactions and aggressive behavior both increased. Avoidance index was also lower in the small pen (indicative of the inability of subordinate pigs to escape from aggressors). In concurrence with the findings of Salak-Johnson skin lesion counts were higher in pigs in the small pen and progressively decreased as space increased. Overall, the results indicated that a minimum space of between 2.4 and $3.6 \mathrm{~m}^{2}$ per sow was necessary to promote good welfare as measured by the behavioral indicators used (Weng et al., 1998).

Use of physiological measures indicative of ability to cope has been used by some research groups to look at effects of space on welfare. One study looked at three 
space allocations $\left(1,2\right.$ and $\left.3 \mathrm{~m}^{2}\right)$ in group housed gilts (6 animals per group). Measures taken included; blood plasma corticosteroid concentration and reproductive parameters such as oestrus detection and mating rate. A lower percentage of gilts were detected in oestrus and were mated in the lower space allocation groups (oestrus detection rates of 79, 88 and 100\%). There was also a significant increase in plasma corticosteroid concentration in the groups housed at $1 \mathrm{~m}^{2}$. These results suggest that a chronic stress response as implied by the elevated corticosteroid concentrations at the lower space allowance may have an effect on reproductive measures (Hemsworth et al., 1986). Similarly, post-pubertal gilts housed in large groups causing a reduction of space allowance to less than 0.9 $\mathrm{m}^{2} /$ gilt showed an increase of undetected oestrus from 3.8-8.0\% (Cronin et al., 1983). The study of Hemsworth et al. (1986) gives us an indication that an optimal housing density for gilts may lie somewhere between 1 and $2 \mathrm{~m}^{2}$ allocations per pig.

In a study with a differing purpose, of determining the effect of stress during mid -gestation on hypothalamic pituitary axis parameters and production, the effects of crowding (space allocation of less than $0.9 \mathrm{~m}^{2}$ per animal) and applied heat were evaluated. This study produced counterintuitive results in that mean glucocorticoid concentration were lower in stressed animals compared to controls. This was hypothesized to be either due to an increased metabolic clearance rate in stress, or a decrease in adrenal production with physiological adaptation (Kattesh et al., 1980).

Barnett used space allocations of 1.97 or $0.98 \mathrm{~m}^{2}$ per sow in groups of four pregnant gilts and assessed welfare parameters, including skin lesions, behavioral changes, free cortisol and cell mediated immunity following injection of a mitogen. Free cortisol was higher and cell mediated immunity lower in the smaller pens. Aggressive interactions were looked at for $90 \mathrm{~m}$ following grouping of unfamiliar pigs and interestingly agonistic encounters were fewer in pens with smaller space allowance. Lesion numbers were unchanged between treatments. An additional treatment in this study involved the use of partial stalls. The provision of these, with feeding within them, reduced free cortisol and increased cell mediated immunity in comparison with the treatments with no stalls (Barnett et al., 1992).

In a more recent study, the effect of higher space allowances on welfare related parameters in sows were investigated. In comparison with earlier studies a relatively large group of mixed parity sows (34 animals) was housed in dynamic group pens with the use of electronic sow feeders. Space allocations of $3 \mathrm{~m}^{2}$ and $2.25 \mathrm{~m}^{2}$ were assigned per animal and to create a dynamic group peri-parturient sows were replaced every 5 weeks with recently inseminated sows. Welfare related parameters studied included agonistic behavior, skin lesion score and salivary cortisol. No differences were observed for fighting activity or production; however mean number of injuries was lower in the larger pen size as were one- way aggressions noted soon after grouping. These results suggest that under these management conditions a higher space allowance would promote better welfare (Remience, 2008)

\section{CONCLUSION}

A number of general conclusions can be drawn from the body of data on space allowance effects on welfare and productivity in both adult pigs and growers. In summary, increased space is likely to reduce aggressive interactions and total skin lesion score and decrease physiological indicators of stress such as free plasma cortisol concentrations. In terms of pig productivity, in general, performance appears to be reduced in conditions of "crowding" although there are some conflicting results in this area of study. There is also fairly convincing evidence from a number of studies on the effect of increased space in gilts on improving oestrus detection rates.

Whilst a number of studies have attempted to quantify space requirements for sows in terms of optimizing welfare and productivity, comparison between studies to suggest a suitable figure is problematic due to variations in group sizes used and management factors such as feeding. In addition much of this study is reported in older literature and given the increased size of the modern pig, may not hold true today. There have also been few attempts to ascertain whether and to what extent parity may have an effect on space allowance. This it appears is an avenue for further research in well controlled studies and results from this will form a good basis for later studies looking further into group sizes and aggression minimizing strategies.

\section{REFERENCES}

Andersen, I.L., K.E. Boe and K. Hove, 2000. Behavioural and physiological thermoregulation in groups of pregnant sows housed in a kennel system at low temperatures. Can. J. Anim. Sci., 80: 1-8.

Barnett, J.L., P.H. Hemsworth, G.M. Cronin, E.A. Newman and T.H. McCallum et al., 1992. Effects of pen size, partial stalls and method of feeding on welfare-related behavioral and physiological responses of group-housed pigs. Applied Anim. Behav. Sci., 34: 207-220.

Beattie, V.E., N. Walker and I.A. Sneddon, 1996. An investigation of the effect of environmental enrichment and space allowance on the behavior and production of growing pigs. Applied Anim. Behav. Sci., 48: 151-158. 
Beattie, V.E., N. Walker and I.A. Sneddon, 1995. Effects of environmental enrichment on behavior and productivity of growing pigs. Anim. Welfare, 4: 207-220.

Bogner, H., 1982. Ethological demands in the keeping of pigs. Applied Anim. Ethol., 8: 301-305.

Bronson, F.H. and B.E. Eleftheriou, 1963. Adrenal responses to crowding in Peromyscus and C57BL/10J mice. Physiol. Zool., 36: 161-166.

Brumm, M.C. and P.S. Miller, 1996. Response of pigs to space allocation and diets varying in nutrient density. J. Anim. Sci. 74: 2730-2737. PMID: 8923187

Brumm, M.C., 1996. Effect of space allowance on barrow performance to 136 kilograms body weight. NCR-89 Committee on Management of Swine. J. Anim. Sci., 74: 745-749. PMID: 8727994

Cale, W.H., 1979. Housing of breeding stock. Australian Pig Industry Research Committee.

Christian, J.J., 1955. Effect of population size on the adrenal glands and reproductive organs of male mice in populations of fixed size. Am. J. Physiol., 182: 292-300. PMID: 13258805

Cronin, G.M., P.H. Hemsworth, C.G. Winfield, B. Muller and W.A. Chamley, 1983. The incidence of and factors associated with, failure to mate by 245 days of age in the gilt. Anim. Reprod. Sci., 5: 199-205.

Ewbank, R. and M.J. Bryant, 1972. Aggressive behavior amongst groups of domesticated pigs kept at various stocking rates. Anim. Behav., 20: 21-28. DOI: 10.1016/S0003-3472(72)80169-6

Ford, J.J. and H.S. Teague, 1978. Effect of floor space restriction on age at puberty in gilts and on performance of barrows and gilts. J. Anim. Sci., 47: 828-832.

Fraser, A.F. and D.M. Broom, 1990. Farm Animal Behavior and Welfare. 3rd Edn., CAB International, Wallingford, ISBN-10: 0851991602 pp: 437.

Gehlbach, G.D., D.E. Becker, J.L. Cox, B.G. Harmon and A.H. Jensen, 1966. Effects of Floor Space Allowance and Number per Group on Performance of Growing-Finishing Swine. J. Anim. Sci., 25: 386-391.

Gonyou, H.W. and W.R. Stricklin, 1998. Effects of floor area allowance and group size on the productivity of growing/finishing pigs. J. Anim. Sci., 76: 1326-1330.

Heitman, H., L. Hahn, C.F. Kelly and T.E. Bond, 1961. Space allotment and performance of growingfinishing swine raised in confinement. J. Anim. Sci., 20: 543-546.
Hemsworth, P.H., J.L. Barnett, C. Hansen and C.G. Winfield, 1986. Effects of social environment on welfare status and sexual behavior of female pigs. II. Effects of space allowance. Appl. Anim. Behav. Sci., 16: 259-267.

Humik, J.F. and N.J. Lewis, 1991. Use of body surface area to set minimum space allowances for confined pigs and cattle. Can. J. Anim. Sci., 71: 577-580.

Hyun, Y., M. Ellis and R.W. Johnson, 1998. Effects of feeder type, space allowance and mixing on the growth performance and feed intake pattern of growing pigs. J. Anim. Sci., 76: 2771-2778. PMID: 9856385

Jensen, A. H., D.E. Becker and B.G. Harmon, 1966. Management factors and young pig performance. J. Anim. Sci., 25: 1273.

Jensen, A.H. and S.E. Curtis, 1976. Effects of group size and of negative air ionization on performance of growing-finishing swine. J. Anim. Sci., 42: 8-11.

Jensen, A.H., 1971. Biological implications of intensive swine rearing systems. J. Anim. Sci., 31: 560-565.

Kattesh, H.G., E.T. Kornegay, J.W. Knight, F.G. Gwazdauskas and H.R. H.R. Thomas et al., 1980. Glucocorticoid concentrations, corticosteroid binding protein characteristics and reproductive performance of sows and gilts subjected to applied stress during mid-gestation. J. Anim. Sci., 50: 897905. PMID: 7390944

Kuhlers, D.L., S.B. Jungst, D.N. Marple and C.H. Rahe, 1985. The effect of pen density during rearing on subsequent reproductive performance in gilts. J. Anim. Sci., 61: 1066-1069. PMID: 4077751

Meunier-Salaun, M.C., M.N. Vantrimponte, A. Raab and R. Dantzer, 1987. Effect of floor area restriction upon performance, behavior and physiology of growing-finishing pigs. J. Anim. Sci., 64: 1371-1377. PMID: 3583943

Moser, R.L., S.G. Cornelius, J.E. Pettigrew, H.E. Hanke and C.D. Hagen, 1985. Response of growing-finishing pigs to decreasing floor space allowance and (or) virginiamycin in diet. J. Anim. Sci., 61: 337-342. PMID: 3930458

Pickett, R.A., W.H. Fugate, R.B. Harrington, T.W. Perry and T.M. Curtin, 1969. Influence of feed preparation and number of pigs per pen on performance and occurrence of esophagogastric ulcers in swine. J. Anim. Sci., 28: 837-841. PMID: 5390353

Randolph, J.H., G.L. Cromwell, T.S. Stahly and D.D. Kratzer, 1981. Effects of group size and space allowance on performance and behavior of swine. J. Anim. Sci., 53: 922-927. 
Remience, V., 2008. Effects of space allowance on the welfare of dry sows kept in dynamic groups and fed with an electronic sow feeder. Appl. Anim. Behav. Sci., 112: 284-296.

Ross, M.C. and S.E. Curtis, 1976. Space allowance and pig behavior. J. Anim. Sci.,

Salak-Johnson, J. L., S.R. Niekamp, S.L. RodriguezZas, M. Ellis and S.E. Curtis, 2007. Space allowance for dry, pregnant sows in pens: body condition, skin lesions and performance. J. Anim. Sci., 85: 1758-1769. PMID: 17371790

ECVSC, 1997. The Welfare of Intensively Kept Pigs. 1st Edn., European Commission, Brussels, pp: 191.

Spicer, H.M. and F.X. Aherne, 1987. The effects of group size/stocking density on weanling pig performance and behavior. Applied Anim. Behav. Sci., 19: $\quad 89-98$. DOI: $10.1016 / 0168-1591$ (87)90206-1

Street, B.R. and H.W. Gonyou, 2008. Effects of housing finishing pigs in two group sizes and at two floor space allocations on production, health, behavior and physiological variables. J. Anim. Sci., 86: 982-991. PMID: 17965323
Weng, R.C., S.A. Edwards and P.R. English, 1998. Behavior, social interactions and lesion scores of group-housed sows in relation to floor space allowance. Appl. Anim. Behav. Sci., 59: 307-316.

Wolter, B.F., M. Ellis, S.E. Curtis, E.N. Parr and D.M. Webel, 2000. Group size and floor-space allowance can affect weanling-pig performance. J. Anim. Sci., 78: 2062-2067. PMID: 10947088

Young, M.G., M.D. Tokach, F.X. Aherne, S.S. Dritz and R.D. Goodband et al., 2008. Effect of space allowance during rearing and selection criteria of performance of gilts over three parities in a commercial swine production system. J. Anim. Sci., 86: 3181-3193. PMID: 18567731 